\title{
Physical activity patterns in a nationally representative sample of adults in Ireland
}

\author{
MBE Livingstone ${ }^{1, *}$, PJ Robson ${ }^{1}$, S McCarthy ${ }^{2}$, M Kiely $^{3}$, K Harrington $^{2}$, P Browne ${ }^{1}$, \\ $M$ Galvin ${ }^{3}$, NU Wareham ${ }^{4}$ and KL Rennie ${ }^{4}$ \\ Irish Universities Nutrition Alliance (IUNA) at: 'Northern Ireland Centre for Diet and Health (NICHE), \\ University of Ulster, Coleraine, Co. Londonderry, BT52 1SA, Northern Ireland: 'Department of Clinical Medicine, \\ Trinity Centre for Health Sciences, St James's Hospital, Dublin 8, Republic of Ireland: ${ }^{3}$ Nutrition Sciences, \\ Department of Food Science and Technology, University College, Cork, Republic of Ireland: \\ ${ }^{4}$ Institute of Public Health, University of Cambridge, Cambridge, CB2 2SR, UK
}

\begin{abstract}
Objective: To evaluate habitual levels of physical activity in a nationally representative sample of adults in Ireland.

Design: Cross-sectional survey using a self-administered questionnaire. Usual levels of work, recreational and household activities were evaluated in relation to anthropometric, demographic and socio-economic characteristics. The amount and intensity of all activities were quantified by assigning metabolic equivalents (METS) to each activity.

Setting: Republic of Ireland and Northern Ireland, 1997-1999.

Subjects: Random sample of 1379 adults aged 18-64 years.

Results: Men were approximately twice as active in work and recreational activity $(139.7 \pm 83.9$ METS) as women $(68.5 \pm 49.8$ METS; $P<0.001)$, but women were three times more active in household tasks (65.9 \pm 58.7 METS vs. $22.6 \pm 24.6$ METS; $P<0.001$ ). Overall levels of physical activity declined with increasing age, particularly leisure activity in men. In women the decline in work activity was offset by spending more time in household pursuits. Twenty-five per cent of the subjects were extremely overweight (body mass index (BMI) $>28 \mathrm{~kg} \mathrm{~m}^{-2}$ ) or obese $\left(\right.$ BMI $\left.>30 \mathrm{~kg} \mathrm{~m}^{-2}\right)$. Fewer obese subjects reported higher levels of work and leisure activities. However, a higher percentage of obese women reported participation in the higher levels of household activities. Participation rates in recreational activities were low. Walking was the most important leisure activity of both men (41\%) and women (60\%). In terms of hours per week spent in vigorous physical activity, men were more active than women, professional and skilled non-manual women were more active than women in other social classes, and younger subjects (aged 18-35 years) were more active than older subjects.

Conclusions: The holistic approach used in the assessment of physical activity in this study has revealed important and subtle differences in the activity patterns of men and women. Failure to fully characterise the respective activity patterns of men and women could lead to ill-informed public health policy aimed at promoting and sustaining lifetime habits of physical activity. The results suggest that simple population-focused programmes to promote physical activity are unlikely to offer the same chance of long-term success as more sensitive and individualised strategies.
\end{abstract}

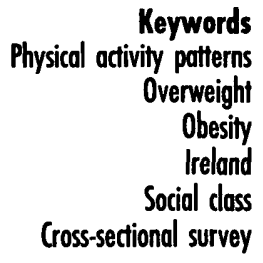

During the course of the last century, changes in lifestyle have had a profound impact on patterns of energy expenditure and physical activity in affluent countries. Increased mechanisation in the workplace has markedly reduced the need for moderate and high intensity activity. In the home, the energy cost of housework has also been minimised while television viewing and related pursuits now monopolise much of the available leisure time of a significant proportion of the population. As a result, predominantly sedentary populations can survive with minimal exertion and can achieve energy equilibrium at a level of energy expenditure below that considered optimal for health.

Epidemiological evidence has demonstrated that physically inactive adults are at increased risk of various chronic diseases including coronary heart disease ${ }^{1-7}$, 
hypertension $^{8,9}$, non-insulin-dependent diabetes mellitus $^{10,11}$, osteoporosis ${ }^{12-14}$, various cancers ${ }^{15-17}$, anxiety and depression ${ }^{18}$ as well as all-cause mortality ${ }^{19-22}$. The influence of an inactive lifestyle on weight regulation is more complex, since the relative contributions made by overeating and inactivity in long-term positive energy balance are unclear. While there is little doubt that a sedentary lifestyle is implicated in the aetiology of obesity, there is a paucity of longitudinal data examining the role of physical activity in body weight control. Indices of a sedentary lifestyle, such as the number of cars per household or hours watching TV per week, provide only indirect evidence of a causal relationship ${ }^{23}$. Nevertheless, participation in physical activity is one of the best predictors of success in long-term maintenance of weight reduction $^{24-26}$, and for attenuating weight gain over time in healthy adults ${ }^{27-29}$.

It appears that physical activity does not have to be vigorous in order to produce health benefits. Recent reports ${ }^{30,31}$ emphasise that substantial health benefits can result by accumulating 30 minutes or more of moderateintensity activity on most - and preferably all - days of the week. Moreover, because the total amount of activity is more important than its form, intensity or duration, the benefits can be accrued by participating in a variety of structured and unstructured activities. However, while the benefits of regular physical activity are well-documented and exercise is now included in most health promotion recommendations, it is clear that while activity levels are variable, overall, only a minority of adults in the USA ${ }^{32,33}$ and Europe $e^{34-38}$ are sufficiently active for health. The lowest levels of inactivity are observed in women ${ }^{32-35,38}$, older adults ${ }^{32-35,38}$ and those with a lower level of education $^{32-35,38-40}$.

To date there has been no comprehensive analysis of the usual levels of physical activity in a nationally representative sample of the Irish population. Consequently the aim of the present study was to evaluate their habitual levels of physical activity in self-reported occupational, recreational and household pursuits in relation to anthropometric, demographic and socioeconomic characteristics.

\section{Methods}

The assessment of habitual levels of physical activity of a random sample of 1379 Irish adults aged 18-64 years was carried out as part of the North/South Ireland Food Consumption Survey (NSIFCS). In brief, the primary aim of the survey was to establish a database of the habitual food and drink consumption of a representative sample of Irish adults. Supplementary information was also collected on anthropometry, employment status, sociodemographic variables, lifestyle factors, smoking habits, alcohol consumption, usual levels of physical activity, health status and attitudes, medication and supplement use. The methods used in the survey, including recruitment procedures, are described in detail elsewhere ${ }^{41}$. The main phase of the fieldwork started in October 1997 and data collection was completed in October 1999.

Body weight in light indoor clothing and without shoes was measured to the nearest $0.1 \mathrm{~kg}$ (Seca Alpha model 707; Seca, Hamburg, Germany) and height to the last completed $0.1 \mathrm{~cm}$ using a free-standing portable stadiometer. The body mass index (BMI) of each subject was calculated as weight in kilograms divided by the squared height in metres $\left(\mathrm{kg} \mathrm{m}^{-2}\right)$. According to the criteria of the International Obesity Task Force ${ }^{42}$, overweight or preobesity was defined as a BMI between 25 and $29.99 \mathrm{~kg} \mathrm{~m}^{-2}$ and obesity as BMI $>30 \mathrm{~kg} \mathrm{~m}^{-2}$. No further subdivision by grade of obesity (1,2 or 3 ) was made in this analysis.

The division of the sample into social class groups was based on the respondents' occupation (including last main occupation for those not working or retired) or, if the respondent was not the head, the head of household's occupation. All subjects were classified according to the UK Standard Occupational Classification of the Office of Population Censuses and Surveys (OPCS) ${ }^{43}$ and the Central Statistics Office, Census 96 Occupations of the Republic of Ireland ${ }^{44}$. However, because of the broad similarity between the two systems of classification and for simplicity and consistency with other surveys, the OPCS system was adopted for all subjects in this study. In addition, the OPCS social class categories have been reduced to four categories (professional, managerial and technical; skilled non-manual; skilled manual; partly skilled and unskilled) in order to provide large enough samples to examine the results separately for men and women from different age groups.

Levels of customary physical activity were assessed by a self-administered questionnaire that was developed at the Institute of Public Health, University of Cambridge. The questionnaire consisted of three sections: activity at home, work and recreation. Information on physical activity was collected in the context in which it was undertaken, and in such a way that the data could be analysed according to the dimension of physical activity of interest. In each case, questions were closed rather than open-ended, to make them easy to complete and to facilitate large-scale data entry. Under household pursuits, the amount of time spent on TV viewing and related activities, stair climbing, shopping, cooking, cleaning and care-giving were queried in detail. Questions on occupational activity were derived from the Modified Tecumseh Occupational Activity Questionnaire, which has been validated elsewhere ${ }^{45,46}$. Subjects were questioned on the mode of travel to and from work, and the duration of work of varying intensities while sitting, standing and walking. In addition, subjects were asked about frequency of stair climbing, kneeling and squatting. The leisure time section was based on the validated Minnesota 
Leisure Time Activity Questionnaire ${ }^{47,48}$ with activities ordered according to the frequency in a UK population ${ }^{34}$. Respondents were asked to identify the frequency and duration of their participation in 36 named recreational pursuits, including sports and gardening activities. For each activity, respondents indicated the number of times they performed the activity in the past year and the average duration per episode. For activities that could involve varying levels of intensity such as walking and gardening, subjects were also asked to indicate the level of intensity of such activities. An additional open-ended question assessed information on recreational physical activities not specified in the questionnaire.

The intensity of all self-reported physical activity in work, household and recreational activities was expressed as an activity metabolic equivalent (MET) index by assigning a multiple of resting metabolic rate (MET score) to each activity. One MET score is equivalent to the energy expenditure during seated rest, approximately $3.5 \mathrm{ml}$ of oxygen consumed per kilogram of body weight per minute. Metabolic equivalents therefore represent the ratio of work metabolic rate to resting metabolic rate and are independent of body weight ${ }^{49}$. Metabolic equivalent levels were obtained for each activity from the compendium of physical activities developed by Ainsworth et al. ${ }^{49}$. The time spent in each activity was multiplied by the appropriate MET score and subsequently summed over all activities to give an overall estimate of MET hours per week (referred to as METS in this study). METS therefore represent both the amount and relative intensity of physical activity during the week for each subject.

The overall weekly MET hours for leisure time (LeisureMETS), work (Work-METS) and household (Home-METS) activity were computed. Total-METS were calculated by summing Leisure-METS and Work-METS. Additionally, the time spent on various recreational activities, including vigorous activities (any activity of 5.0 MET or more) and TV viewing and related pursuits was also reported.

\section{Statistical analysis}

Statistical analysis was carried out using SPSS for Windows version 9.0.1 (SPSS Inc., Chicago, IL). Physical characteristics and time spent in various activities were summarised using mean \pm standard deviation (SD), whereas the distributions of MET values were described using 25th, 50th and 75th percentiles. Differences between the mean values were assessed using independent samples $t$-tests or one-way analysis of variance (ANOVA), and Mann-Whitney $U$-tests were used to assess differences in median values obtained for METS derived for males and females. $P$-values less than 0.05 were considered to be statistically significant.

\section{Results}

\section{Sample description}

The physical characteristics of the subjects are presented in Table 1. As a group, men were significantly taller, heavier and fatter than women (all $P<0.001$ ), but in both groups average BMI increased with increasing age. With the exception of the youngest women, the mean BMI of all groups was in the overweight category. The 75th percentile of BMI was 29.2 and $28.1 \mathrm{~kg} \mathrm{~m}^{-2}$ for men and women, respectively, indicating that approximately $25 \%$ of each group was extremely overweight or obese.

\section{Men vs. women}

Men were significantly more active overall than women, and in different ways. When comparing mean $( \pm S D)$ levels of activity, men were approximately twice as active in work and recreational activity (139.7 \pm 83.9 METS) as women $(68.5 \pm 49.8$ METS), but women were three times more active in household tasks $(65.9 \pm 58.7$ METS vs. $22.6 \pm 24.6$ METS). Time spent on TV viewing and related pursuits was similar for men $\left(19 \pm 10 \mathrm{~h} \mathrm{week}^{-1}\right)$ and women $\left(18 \pm 10 \mathrm{~h} \mathrm{week}^{-1}\right)$. Twenty-five per cent of the subjects spent $25 \mathrm{~h}^{\text {week }}{ }^{-1}$ in these pursuits.

Of the 12 recreational activities in which subjects participated at least once a week, walking for pleasure was by far the most important for both men (41\%) and women (60\%), followed by gardening and floor exercises (Table 2). Thereafter, gender differences emerged in the type of leisure-time activities undertaken but, overall, men spent significantly more time in vigorously active

Table 1 Description of the subjects

\begin{tabular}{|c|c|c|c|c|c|c|c|c|c|c|}
\hline & \multirow[b]{2}{*}{ Age group } & \multicolumn{3}{|c|}{ Height (m) } & \multicolumn{3}{|c|}{ Weight (kg) } & \multicolumn{3}{|c|}{ BMI $\left(\mathrm{kg} \mathrm{m}^{-2}\right)$} \\
\hline & & $n$ & Mean & SD & $n$ & Mean & SD & $n$ & Mean & SD \\
\hline Females & $\begin{array}{l}18-35.9 \text { years } \\
36-50.9 \text { years } \\
51-64.9 \text { years } \\
\text { Total } \\
18-35.9 \text { years } \\
36-50.9 \text { years } \\
51-64.9 \text { years } \\
\text { Total }\end{array}$ & $\begin{array}{l}240 \\
217 \\
156 \\
613 \\
265 \\
281 \\
152 \\
698\end{array}$ & $\begin{array}{l}1.77 \\
1.75 \\
1.73 \\
1.75^{*} \\
1.63 \\
1.62 \\
1.60 \\
1.62\end{array}$ & $\begin{array}{l}0.07 \\
0.06 \\
0.07 \\
0.07 \\
0.06 \\
0.06 \\
0.06 \\
0.06\end{array}$ & $\begin{array}{l}249 \\
235 \\
171 \\
655 \\
269 \\
285 \\
160 \\
714\end{array}$ & $\begin{array}{l}81.0 \\
84.8 \\
83.2 \\
82.9^{\star} \\
64.6 \\
68.2 \\
71.0 \\
67.5\end{array}$ & $\begin{array}{l}13.3 \\
13.6 \\
13.6 \\
13.3 \\
11.6 \\
12.3 \\
13.3 \\
12.5\end{array}$ & $\begin{array}{l}240 \\
217 \\
156 \\
613 \\
265 \\
281 \\
152 \\
698\end{array}$ & $\begin{array}{l}25.8 \\
27.7 \\
27.6 \\
26.9^{\star} \\
24.4 \\
26.1 \\
27.8 \\
25.8\end{array}$ & $\begin{array}{l}3.6 \\
4.3 \\
3.6 \\
4.0 \\
4.3 \\
4.4 \\
5.5 \\
4.8\end{array}$ \\
\hline
\end{tabular}

" Significantly different from females, $P<0.001$ (independent samples t-test). 
Table 2 Leisure-time activitiest - percentages of subjects participating in each activity once a week or more

\begin{tabular}{|c|c|c|c|}
\hline \multicolumn{2}{|c|}{ Males $(n=648)$} & \multicolumn{2}{|c|}{ Females $(n=705)$} \\
\hline Activity & $\begin{array}{l}\% \text { of males participating } \\
\text { once a week or more }\end{array}$ & Activity & $\begin{array}{l}\% \text { of females participating } \\
\text { once a week or more }\end{array}$ \\
\hline $\begin{array}{l}\text { Walking for pleasure } \\
\text { Mowing the lawn } \\
\text { DIY } \\
\text { Floor exercises } \\
\text { Football/rugby/hockey } \\
\text { Watering the garden } \\
\text { Digging, shovelling, or chopping wood } \\
\text { Weeding, pruning } \\
\text { Jogging } \\
\text { Snooker/billiards/darts } \\
\text { Exercises with weights } \\
\text { Golf }\end{array}$ & $\begin{array}{r}41.1 \\
28.5 \\
17.3 \\
15.3 \\
15.2 \\
14.7 \\
14.3 \\
12.0 \\
10.1 \\
9.8 \\
9.7 \\
9.2\end{array}$ & $\begin{array}{l}\text { Walking for pleasure } \\
\text { Watering the garden } \\
\text { Floor exercises } \\
\text { Weeding, pruning } \\
\text { Mowing the lawn } \\
\text { Conditioning exercises } \\
\text { Dancing } \\
\text { General swimming } \\
\text { Exercises with weights } \\
\text { Musical instrument playing } \\
\text { Step/high impact aerobics } \\
\text { Competitive/lap swimming }\end{array}$ & $\begin{array}{r}60.3 \\
20.1 \\
19.1 \\
15.1 \\
14.8 \\
11.8 \\
10.7 \\
7.9 \\
5.7 \\
5.7 \\
5.4 \\
4.9\end{array}$ \\
\hline
\end{tabular}

$\dagger$ Twelve most frequently undertaken activities, listed for each sex.

recreational pursuits than women $\left(1.7 \pm 2.7 \mathrm{hweek}^{-1}\right.$ men vs. $1.0 \pm 1.7 \mathrm{~h}$ week ${ }^{-1}$ women, $P<0.001$; Fig. 1 ).

\section{Age}

The overall trend was for a decline in all types of physical activity with increasing age (Table 3 ). Compared with the youngest age group, median Total-METS derived for the oldest subjects decreased by approximately $25 \%$ in men and $50 \%$ in women. However, gender differences in the pattern of this decline were apparent. While the work and household activity levels of men were maintained until age 51 years, the decline in leisure-time activity was evident at a younger age. Consequently, in the oldest age group, median METS declined by $20-30 \%$ in work and household activity but by $50 \%$ in leisure-time pursuits. In contrast, while women spent significantly less time in leisure-time activities at all ages compared with men, nevertheless they sustained these levels across the ages. In the oldest age group, half of the women undertook no work-related activity, but compensated by spending more time in household pursuits.

There were no age-related trends in the amount of time spent watching TV, but with increasing age, the time spent in vigorous leisure-time activity declined significantly in both men and women (Fig. 1). Thus, the amount of time spent in vigorous physical activity by the youngest men $\left(2.72 \pm 3.28 \mathrm{~h}\right.$ week $\left.^{-1}\right)$ and women $\left(1.44 \pm 2.02 \mathrm{hweek}^{-1}\right)$ had declined to $0.60 \pm 1.6 \mathrm{hweek}^{-1}$ and $0.40 \pm 0.94 \mathrm{hweek}^{-1}$ in the oldest men and women, respectively $(P<0.05$;

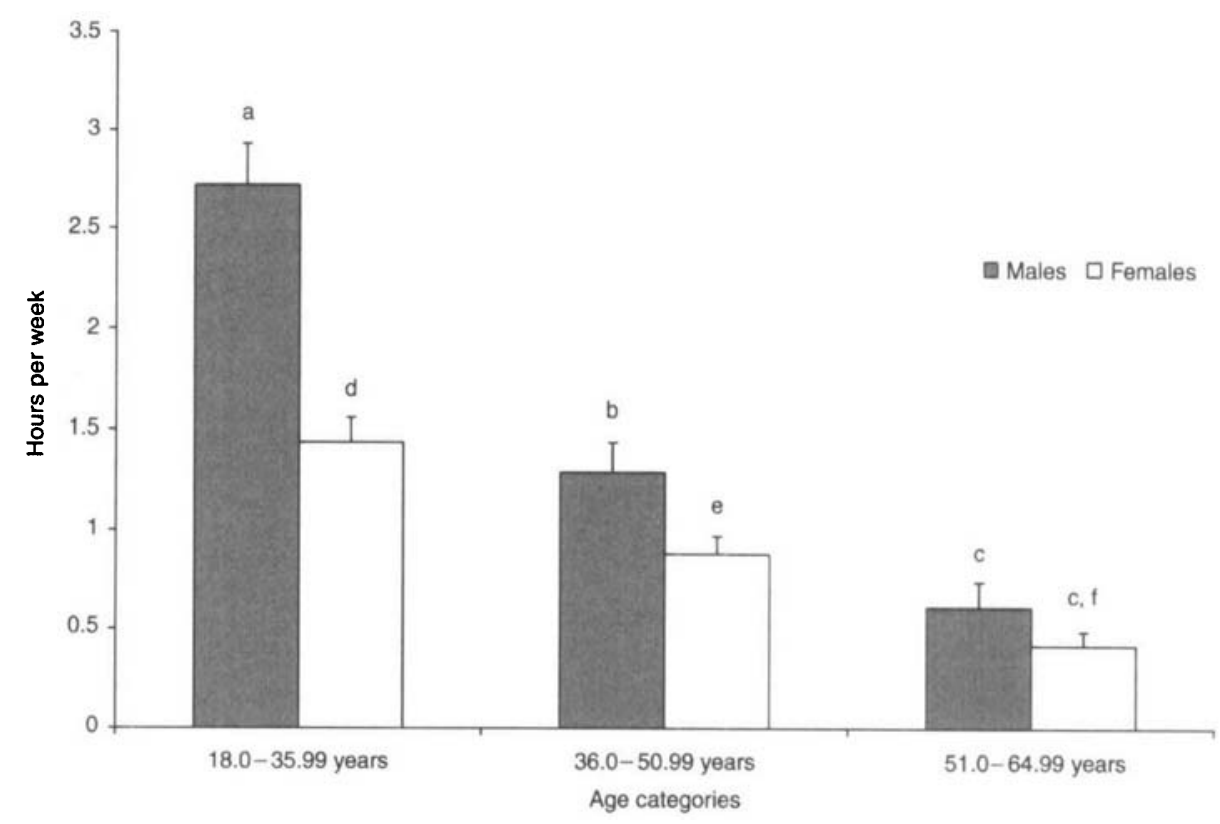

Fig. 1 Hours per week spent in vigorous physical activity by subjects in each age group. Values are mean and standard error of mean (SEM). For each sex, differences between BMI categories assessed using ANOVA with LSD. Within each BMI category, differences between sexes assessed using independent samples $t$-tests. Values with different superscripts are significantly different at $P<0.05$ 
Table 3 Energy expenditure estimates (METS) for total, work, leisure and home activities, for different age categories

\begin{tabular}{|c|c|c|c|c|c|c|c|c|c|c|c|c|}
\hline & \multicolumn{12}{|c|}{ METSt } \\
\hline & \multicolumn{3}{|c|}{ Total (percentiles) } & \multicolumn{3}{|c|}{ Work (percentiles) } & \multicolumn{3}{|c|}{ Leisure (percentiles) } & \multicolumn{3}{|c|}{ Home (percentiles) } \\
\hline & 25th & 50 th & 75th & 25th & 50 th & 75th & 25th & 50th & 75th & 25th & 50 th & 75th \\
\hline \multicolumn{13}{|l|}{ Males $(n=648)$} \\
\hline $18-35.9$ years & 90.1 & 135.5 & 200.7 & 60.9 & 92.7 & 152.5 & 15.8 & 30.6 & 52.7 & 6.7 & 14.8 & 30.5 \\
\hline $36-50.9$ years & 93.8 & 140.5 & 195.6 & 65.4 & 102.4 & 132.9 & 9.1 & 21.2 & 38.6 & 6.6 & 15.4 & 35.3 \\
\hline $51-64.9$ years & 60.2 & 104.3 & 152.6 & 28.7 & 70.5 & 133.7 & 9.2 & 16.4 & 37.4 & 3.0 & 10.4 & 24.7 \\
\hline Total & 87.8 & 127.4 & 186.6 & 59.3 & 91.8 & 147.0 & 10.5 & 23.7 & 44.3 & 5.4 & 13.9 & 29.4 \\
\hline \multicolumn{13}{|c|}{ Females $(n=705)$} \\
\hline $18-35.9$ years & 45.5 & 80.0 & 104.4 & 27.3 & 60.0 & 78.8 & 7.4 & 15.7 & 28.2 & 20.3 & 42.4 & 88.3 \\
\hline $36-50.9$ years & 29.1 & 61.5 & 86.4 & 0.7 & 43.8 & 71.6 & 6.7 & 13.0 & 25.2 & 44.0 & 68.7 & 94.0 \\
\hline $51-64.9$ years & 14.1 & 38.6 & 81.5 & 0.0 & 0.0 & 63.9 & 5.4 & 14.5 & 27.6 & 39.8 & 61.0 & 86.4 \\
\hline Total & 29.0 & $64.8^{*}$ & 94.3 & 0.0 & $49.0^{*}$ & 74.1 & 6.7 & $14.2^{\star}$ & 26.8 & 33.3 & $58.8^{*}$ & 90.3 \\
\hline
\end{tabular}

$\dagger$ Multiples of resting metabolic rate $\times$ hours per week.

- Significantly different from males, $P<0.001$ (Mann-Whitney $U$-test).

ANOVA with least significant difference (LSD)). Fifty per cent of the latter group reported no vigorous recreational physical activity.

\section{BMI}

The mean values for BMI and the prevalence of overweight and obesity in men and women for each of the quartiles of Total-, Work-, Leisure- and Home-METS are presented in Table 4. Higher levels of total work and recreation activities were associated with a trend towards lower BMI, in both men and women. For home-related activities, however, this trend was reversed in women and was no longer apparent in men. No clear pattern emerged in the activity levels of overweight subjects, with the exception of work activity of women. Fewer overweight women were involved at higher levels of work activity, and this in turn largely accounted for the overall trend towards a decline in total activity levels with increasing fatness. An inverse relationship was observed with regard to the percentage of obese subjects who engaged in increasing levels of total, work and leisure activity. Again, the notable exception was home-related activity where the pattern was inconsistent in men, but where a higher percentage of obese women participated in the higher levels of household activities.

Lean men engaged in vigorously active recreation for $1.9 \pm 2.6 \mathrm{~h}$ week $\mathrm{k}^{-1}$ but this was not significantly different from overweight $\left(1.6 \pm 2.7 \mathrm{hweek}^{-1}\right)$ and obese $(1.3 \pm$ $3.0 \mathrm{~h}$ week $^{-1}$ ) men (Fig. 2). However, overweight ( $0.8 \pm$ $\left.1.4 \mathrm{hweek}^{-1}\right)$ and obese women $\left(0.7 \pm 1.5 \mathrm{hweek}^{-1}\right)$

Table 4 Distribution of BMI and prevalence of overweight and obesity among male and female subjects by quartiles of total physical activity (Total-METS), work physical activity (Work-METS), leisure-time physical activity (Leisure-METS) and household physical activity (HomeMETS)

\begin{tabular}{|c|c|c|c|c|c|c|c|c|}
\hline & \multicolumn{4}{|c|}{ BMI $\left(\mathrm{kg} \mathrm{m}^{-2}\right)$} & \multirow{2}{*}{\multicolumn{2}{|c|}{$\begin{array}{l}\text { Percentage overweight } \\
\left(\mathrm{BMI}=25-29.9 \mathrm{~kg} \mathrm{~m}^{-2}\right)\end{array}$}} & \multirow{2}{*}{\multicolumn{2}{|c|}{$\begin{array}{l}\text { Percentage obese } \\
\left(\mathrm{BMI}>30 \mathrm{~kg} \mathrm{~m}^{-2}\right)\end{array}$}} \\
\hline & \multicolumn{2}{|c|}{ Males } & \multicolumn{2}{|c|}{ Females } & & & & \\
\hline & Mean & SD & Mean & SD & Males & Females & Males & Females \\
\hline \multicolumn{9}{|l|}{ Total-METS } \\
\hline 1st quartile & 27.7 & 4.4 & 26.7 & 5.4 & 41.4 & 38.1 & 26.5 & 18.2 \\
\hline 2nd quartile & 26.5 & 3.6 & 25.9 & 4.6 & 45.7 & 32.8 & 15.4 & 15.8 \\
\hline 3rd quartile & 27.0 & 4.2 & 25.2 & 4.5 & 44.4 & 30.5 & 18.5 & 12.4 \\
\hline 4th quartile & 26.6 & 3.6 & 25.5 & 4.5 & 42.0 & 25.7 & 14.2 & 15.4 \\
\hline \multicolumn{9}{|l|}{ Work-METS } \\
\hline 1st quartile & 27.4 & 4.3 & 27.1 & 5.2 & 38.9 & 42.2 & 26.5 & 20.0 \\
\hline 2nd quartile & 26.6 & 3.8 & 25.3 & 4.5 & 46.3 & 26.6 & 14.8 & 13.0 \\
\hline 3rd quartile & 26.9 & 4.0 & 25.4 & 4.6 & 44.2 & 30.9 & 18.4 & 13.1 \\
\hline 4th quartile & 26.9 & 3.8 & 25.4 & 4.6 & 44.1 & 26.7 & 14.9 & 15.3 \\
\hline \multicolumn{9}{|l|}{ Leisure-METS } \\
\hline 1st quartile & 27.6 & 4.4 & 26.2 & 5.1 & 40.7 & 30.6 & 23.5 & 17.9 \\
\hline 2nd quartile & 27.1 & 4.1 & 26.0 & 5.1 & 50.0 & 30.0 & 19.1 & 16.7 \\
\hline 3rd quartile & 26.8 & 3.7 & 25.5 & 4.6 & 40.7 & 33.9 & 17.3 & 12.4 \\
\hline 4th quartile & 26.3 & 3.6 & 25.7 & 4.3 & 42.0 & 32.4 & 14.8 & 14.8 \\
\hline \multicolumn{9}{|l|}{ Home-METS } \\
\hline 1st quartile & 27.2 & 3.9 & 25.2 & 5.0 & 45.5 & 29.5 & 18.8 & 10.8 \\
\hline 2nd quartile & 26.5 & 4.1 & 25.8 & 4.2 & 45.9 & 33.3 & 15.7 & 14.7 \\
\hline 3rd quartile & 26.9 & 3.9 & 26.0 & 5.0 & 37.4 & 32.4 & 21.5 & 17.6 \\
\hline 4th quartile & 27.1 & 4.0 & 26.3 & 4.9 & 44.7 & 31.8 & 18.6 & 18.8 \\
\hline
\end{tabular}




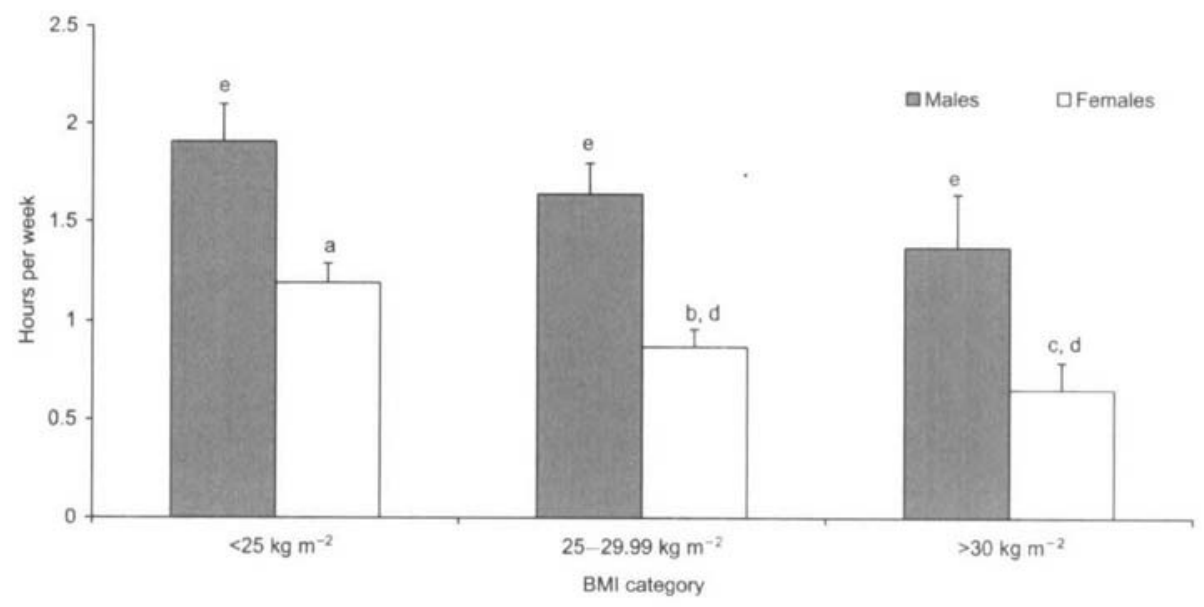

Fig. 2 Hours per week spent in vigorous physical activity by lean, overweight and obese subjects. Values are mean and standard error of mean (SEM). For each sex, differences between BMI categories assessed using ANOVA with LSD. Within each BMI category, differences between sexes assessed using independent samples $t$-tests. Values with different superscripts are significantly different at $P<0.05$

spent significantly less time in these pursuits than lean women $\left(1.2 \pm 0.7 \mathrm{~h} \mathrm{week}^{-1} ; P<0.05\right)$. On average, the overweight and obese spent $2-3$ hours per week more in TV viewing than non-overweight subjects. For men, these differences were not significant. However, obese women watched significantly more TV than lean women (20.2 \pm $11.4 \mathrm{~h} \mathrm{week}^{-1}$ vs. $17.2 \pm 10.4 \mathrm{~h}$ week $\left.^{-1} ; P<0.05\right)$.

\section{Social class}

The impact of social class grouping on activity patterns was less consistent than that of gender, age and BMI. The results in Table 5 demonstrate a trend for professional and skilled non-manual men to engage in less total and workrelated activity than men from other social groups but the trend was reversed in the women. Involvement in household activities by men was broadly similar across social class groupings but women in skilled manual, partly skilled and unskilled occupations spent more time in these activities than women from other social groups.

The time spent in vigorously active recreation by men ranged from $1.2 \pm 2.4 \mathrm{~h}$ week ${ }^{-1}$ (skilled manual) to $2.0 \pm$ $3.4 \mathrm{~h}$ week $^{-1}$ (skilled non-manual) but none of these differences were significant. On the other hand, there was an approximately two-fold difference in the range of time spent in vigorously active recreation by the women

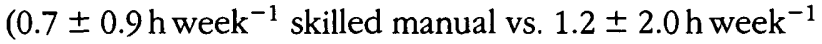
skilled non-manual). Women in professional and skilled non-manual groups spent significantly more time in these pursuits than women in other social class groupings $(P<0.05)$. Clear social class differences were observed in TV viewing habits. The amount of time spent in this activity by professional men $\left(17.3 \pm 9.6 \mathrm{hweek}^{-1}\right)$ and women $\left(16.0 \pm 8.9 \mathrm{~h}^{-1} \mathrm{wek}^{-1}\right)$ was significantly less than that by men $\left(20.8 \pm 9.9 \mathrm{hweek}^{-1}\right)$ and women

Table 5 Energy expenditure estimates (METS) by social class for total, work, leisure and home activity

\begin{tabular}{|c|c|c|c|c|c|c|c|c|c|c|c|c|c|c|}
\hline & \multirow[b]{3}{*}{$n$} & \multirow[b]{3}{*}{$\%$} & \multicolumn{12}{|c|}{ METS $†$} \\
\hline & & & \multicolumn{3}{|c|}{ Total (percentiles) } & \multicolumn{3}{|c|}{ Work (percentiles) } & \multicolumn{3}{|c|}{ Leisure (percentiles) } & \multicolumn{3}{|c|}{ Home (percentiles) } \\
\hline & & & 25th & 50 th & 75th & 25th & 50th & 75th & 25th & 50th & 75th & 25th & 50 th & 75th \\
\hline \multicolumn{15}{|l|}{ Males } \\
\hline $\begin{array}{l}\text { Professional, managerial } \\
\text { \& technical }\end{array}$ & 276 & 42.8 & 81.8 & 116.4 & 162.9 & 59.5 & 81.7 & 132.7 & 9.6 & 22.4 & 38.5 & 5.8 & 16.8 & 33.0 \\
\hline Non-manual skilled & 75 & 11.6 & 69.1 & 101.5 & 160.8 & 51.2 & 70.3 & 119.0 & 13.9 & 22.0 & 41.5 & 8.6 & 14.4 & 27.4 \\
\hline Manual skilled & 160 & 24.8 & 110.3 & 157.9 & 205.2 & 84.6 & 131.1 & 176.8 & 9.5 & 23.4 & 49.0 & 4.2 & 9.7 & 26.9 \\
\hline Partly skilled \& unskilled & 134 & 20.8 & 68.9 & 141.8 & 196.2 & 27.1 & 95.7 & 143.3 & 11.0 & 30.3 & 52.5 & 6.3 & 15.7 & 29.9 \\
\hline Total & 645 & 100 & 82.6 & 127.3 & 187.0 & 59.3 & 91.6 & 147.0 & 10.5 & 23.7 & 44.2 & 5.4 & 13.8 & 29.4 \\
\hline \multicolumn{15}{|l|}{ Females } \\
\hline $\begin{array}{l}\text { Professional, managerial } \\
\text { \& technical }\end{array}$ & 302 & 43.1 & 44.5 & 71.4 & 97.2 & 20.0 & 58.2 & 78.7 & 8.5 & 14.8 & 25.9 & 33.2 & 58.5 & 88.5 \\
\hline $\begin{array}{l}\text { Non-manual skilled } \\
\text { Manual skilled }\end{array}$ & $\begin{array}{l}156 \\
104\end{array}$ & $\begin{array}{l}22.3 \\
14.8\end{array}$ & $\begin{array}{l}39.4 \\
10.5\end{array}$ & $\begin{array}{l}69.1 \\
32.8\end{array}$ & $\begin{array}{l}96.5 \\
75.8\end{array}$ & $\begin{array}{r}17.5 \\
0.0\end{array}$ & $\begin{array}{r}52.3 \\
0.0\end{array}$ & $\begin{array}{l}71.0 \\
62.1\end{array}$ & $\begin{array}{l}7.5 \\
5.5\end{array}$ & $\begin{array}{l}15.3 \\
11.7\end{array}$ & $\begin{array}{l}30.0 \\
25.7\end{array}$ & $\begin{array}{l}26.6 \\
56.3\end{array}$ & $\begin{array}{l}45.4 \\
75.8\end{array}$ & $\begin{array}{r}78.3 \\
118.0\end{array}$ \\
\hline Partly skilled \& unskilled & 139 & 19.8 & 16.4 & 42.5 & 90.0 & 0.0 & 24.2 & 71.8 & 4.5 & 13.0 & 27.6 & 32.5 & 64.0 & 98.6 \\
\hline Total & 701 & 100 & 29.8 & 65.7 & 94.5 & 0.0 & 49.1 & 74.2 & 6.8 & 14.3 & 27.0 & 33.2 & 58.8 & 90.7 \\
\hline
\end{tabular}

† Multiples of resting metabolic ratexhours per week. 
$\left(21.1 \pm 12.5 \mathrm{hweek}^{-1}\right)$ who were classified in other occupations.

\section{Discussion}

In the present study, the usual patterns of physical activity in a representative sample of the Irish adult population were characterised using a comprehensive physical activity questionnaire. The physical activity questionnaire remains one of the most feasible and cost-effective methods for assessing physical activity in the epidemiological context. However, comparisons between studies are bedevilled by measurement error associated with selfreported activities, use of a diversity of definitions of physical activity, differences in the time frame of studies and undue focus in many studies on a relatively narrow range of activities ${ }^{50-53}$. In particular, the overwhelming importance attached to the role of sport and other recreations, to the exclusion of household activities, is highly likely to have biased many assessments of nonoccupational physical activity. As a result, estimates of physical activity by many of the questionnaires used in earlier studies have been shown to relate more closely to physical fitness than habitual activity ${ }^{54}$.

A major strength of the present study is that it provides a detailed assessment of all areas of an individual's daily physical activity (occupational, sports and other recreations and non-sporting, non-occupational activity) and is therefore more likely to appropriately characterise activity levels. With the caveat that direct comparisons between studies is difficult, the present results are broadly consistent with those of previous epidemiological studies of physical activity, namely that men are more active than women and activity levels decline with increasing age and are inversely associated with adiposity in both sexes $^{32-35,38}$.

One of the most significant findings of this survey is the distinction between the physical activity patterns of men and women. Overall, men are twice as active in occupational and leisure-time activities, while women are three times more active in household pursuits. It is conceivable, therefore, that the disparity between the physical activity levels of men and women that has been observed in previous studies which omitted assessments of household activities may be more apparent than real, simply because the questionnaires used have better characterised the physical activity levels of men ${ }^{55-57}$. More all-inclusive studies of physical activity demonstrate that it is not unusual for women to spend at least 2 hours per day in household and family care tasks, compared with about 30 minutes for men ${ }^{58}$. An additional explanation for why the assessment of physical activity may have been more accurate in men than women is that recall and measurement error tend to be greater for light and moderate-intensity activity compared with vigorous activity, which tends to be more time delineated ${ }^{58,59}$.
Consequently, if women perform activities that are mostly of lower intensity, errors in the estimation of their physical activity patterns could be magnified. Given the potential significance of household activities to the overall energy expenditure of women, it could be speculated that the proportion of women who meet current activity recommendations is probably greater than generally perceived ${ }^{55}$. It may also offer a possible explanation for the observations that, in contrast to men, physical activity in women is poorly associated with reduced risk of mortality ${ }^{59-61}$.

Unfortunately, the downward shift in the occupational activity levels of the men with increasing age is not compensated for by increased leisure or household activities. Indeed, leisure-time activity declines at an even greater rate. On the other hand, the activity levels of women are more likely to be sustained over time, through substitution of reduced or no occupational activity with increased levels of activity in household pursuits. While the contribution of work-related activity to total activity should not be underestimated, it is arguably of less interest than non-occupational activity, since it is not normally subject to increases through health promotion efforts. Although it is notoriously difficult to measure accurately, all indications are that work-related activity, even in manual occupations, has declined substantially over recent decades, and will probably continue to do so. Data from Finland suggest that the energy demands of work activity have declined by $225 \mathrm{~kJ}^{\text {day }}{ }^{-1}$ between 1982 and $1992^{62}$. Thus the nature, intensity and duration of non-occupational physical activity are likely to assume even greater significance in dictating the overall pattern of energy expenditure in the future. Nevertheless, just as increased reliance on technology has substantially reduced the energy demands of work activity, so too has it reduced the energy demands of household activity. However, as this study has clearly demonstrated, the latter may be an invaluable adjunct to overall energy expenditure in the face of the declining demands of work activity.

At the same time, realistically achievable inputs of discretionary physical activity in sports and other recreations can have a significant impact in counteracting low levels of work and/or household activities ${ }^{63}$. In this subject group, sport and other recreational activities accounted for about $25 \%$ and $20 \%$ of the estimated overall total MET hours spent in physical activity of the men and women, respectively. In common with earlier studies $^{32,34,38}$, walking for pleasure and gardening were the most frequently selected recreational activities while there was only minimal participation in vigorously active sports. Although TV viewing and related pursuits were considered separately from other leisure-time activities in this survey, it is clear that TV viewing monopolised a major portion of available leisure time.

A possible explanation for the observed decline with increasing age in leisure-time activity by the men might be 
a shift in the type of recreational activities engaged in. The amount of time spent in vigorous recreational activity decreased by $50 \%$ in each of the two older age groups, suggesting that participation in higher intensity recreational activities and team sports at a younger age is subsequently displaced in favour of less physically demanding recreations. Moreover, less time is spent in these activities. On the other hand, the stability with age of leisure-time activities in women, together with a less pronounced decline in vigorous activities (albeit from lower levels in the first place), suggest that they may have adopted more lifetime and individualised leisure pursuits from the outset, and have been able to sustain these over time. Thus, the higher rates of participation in walking by women suggest that greater focus should be placed on increasing activity levels by promoting those activities that can easily be incorporated and sustained within existing lifestyles. Since the health benefits of physical activity are linked principally to the total amount of energy expended ${ }^{2,4,19,29,30}$, the outcomes of this study endorse those of earlier studies and support the need to increase the moderate-intensity leisure-time activity of the population in general, but particularly in those who are employed in sedentary occupations and whose involvement in household tasks is minimal.

The lack of a consistent association between social class and physical activity levels is somewhat at variance with the observation in many studies that levels of physical activity are directly correlated with level of educational attainment ${ }^{32-35,38-40}$. There are a number of possible reasons for this. Firstly, educational status may not be an appropriate proxy measure for social grouping and vice versa. Secondly, since many surveys of physical activity focus on leisure-time activity and do not adequately address occupational and non-sporting, nonoccupational activity, there is likely to have been some misclassification of lower income or less educated subjects who have physically demanding jobs. However, to the extent that TV viewing is an indirect marker of a sedentary lifestyle, the results of this study do indicate higher levels of leisure-time inactivity by subjects in partly skilled and unskilled occupations. Thirdly, the data may simply reinforce the fact that most occupations, even in the manual category, are becoming increasingly sedentary. Finally, the over-representation of subjects from the professional and managerial social group may have resulted in unrepresentative physical activity profiles. It could be argued that if social class and educational status are proxy measures of a cluster of factors (knowledge, time, social support, access to facilities, neighbourhood safety) known to impact on physical activity levels, it may be more instructive to directly assess the impact of these factors on physical activity levels.

The rates of obesity observed in this study group (20\% men, $16 \%$ women) are grounds for considerable concern. A further $5 \%$ of men and $9 \%$ of women are also extremely overweight (BMI $>28 \mathrm{~kg} \mathrm{~m}^{-2}$ ), indicting that current and future levels of obesity in Ireland may be among the highest in Europe ${ }^{64}$. Undoubtedly, low levels of activity are associated with increased risk of weight gain and obesity $^{65}$ and, on balance, the evidence from ecological, cross-sectional and prospective studies ${ }^{23,28,62,66-71}$ suggests that this may be a causal association. While definitive conclusions are not possible, nevertheless recent evidence has shown that the relative impact of a sedentary lifestyle in contributing to obesity may have been substantially underestimated ${ }^{72}$. Overall, the obese subjects in this study had lower levels of activity but because of the cross-sectional approach of this study, it is unclear whether this is a causal association or a post boc effect. The increased levels of household related activity by obese women are of interest, and suggest that they are more successful and motivated than obese men at compensating for their decreased levels of work and recreational physical activity. It is not possible to conclude if their participation in these activities is simply a consequence of their obesity, possibly caused by limitations in their physical and psychological well-being. Nevertheless, the fact that they are motivated to increase physical activity levels in their own homes could usefully be exploited as a strategy to help improve adherence to exercise programmes to aid weight loss and maintenance ${ }^{73,74}$.

In conclusion, accurate assessment of patterns of physical activity is needed to properly inform public health policy aimed at promoting and sustaining lifetime habits of physical activity. Since the health benefits of physical activity are linked principally to the total amount of energy expended, the type of activity performed is of less significance. Occupational activity, sports, conditioning activities, exercise, gardening and household tasks are all potentially beneficial. Consequently, the more holistic assessment of physical activity made in this study has helped to highlight the complex, multidimensional nature of activity and, in particular, has revealed important and subtle differences in the respective physical activity patterns of men and women. The results have a clear and important public health message - simple population-focused programmes to promote physical activity are unlikely to offer the same chance of long-term success as more sensitive and individualised strategies.

\section{Acknowledgements}

We thank the subjects who participated in the survey.

\section{References}

1 Lakka TA, Venäläinen JM, Rauramaa R, Salonen R, Tuomilehto J, Salonen JT. Relation of leisure-time physical activity and cardiorespiratory fitness to the risk of acute myocardial infarction in men. N. Engl. J. Med. 1994; 330: 1549-54. 
2 Leon AS, Connett J, Jacobs DR, Rauramaa R. Leisure-time physical activity levels and risk of coronary heart disease and death: the Multiple Risk Factor Intervention Trial. JAMA 1987; 258: 2388-95.

3 Berlin JA, Colditz GA. A meta-analysis of physical activity in the prevention of coronary heart disease. Am.J. Epidemiol. 1990; 132: 612-28.

4 Hein HO, Suadicani P, Gyntelberg F. Physical fitness or physical activity as a predictor of ischaemic heart disease? A 17-year follow-up in the Copenhagen Male Study. J. Intern. Med. 1992; 232: 471-9.

5 Sandvik L, Erikssen J, Thaulow E, Erikssen G, Mundal R, Rodahl K. Physical fitness as a predictor of mortality among healthy, middle-aged Norwegian men. N. Engl. J. Med. 1993; 328: 533-7.

6 Morris JN, Clayton DG, Everitt MG, Semmence AM, Burgess EH. Exercise in leisure time: coronary attack and death rates. Br. Heart J. 1990; 63: 325-34.

7 Powell KE, Thompson PD, Caspersen CJ, Kendrick JS. Physical activity and the incidence of coronary heart disease. Ann. Rev. Public Health 1987; 8: 253-87.

8 American College of Sports Medicine. Position stand: physical activity, physical fitness, and hypertension. Med. Sci. Sports Exerc. 1993; 10: i-x.

9 Arroll B, Beaglehole R. Does physical activity lower blood pressure? A critical review of the clinical trials. J. Clin. Epidemiol. 1992; 45: 439-47.

10 Manson JE, Nathan DM, Krolewski AS, Stampfer MJ, Willett WC, Hennekens $\mathrm{CH}$. A prospective study of exercise and incidence of diabetes among US male physicians. JAMA 1992; 268: 63-7.

11 Helmrich SP, Ragland DR, Leung RW, Paffenbarger RS. Physical activity and reduced occurrence of non-insulindependent diabetes mellitus. N. Engl. J. Med. 1991; 325: 147-52.

12 Brooke-Wavell $\mathrm{K}$, Jones PRM, Hardmann AE. Brisk walking reduces calcaneal bone loss in post-menopausal women. Clin. Sci. 1997; 92: 75-80.

13 Cummings SR, Kelsey JL, Nevitt MC, O'Dowd KJ. Epidemiology of osteoporosis and osteoporotic fractures. Epidemiol. Rev. 1985; 7: 178-208.

14 Smith EL, Reddan W, Smith PE. Physical activity and calcium modalities for bone mineral increase in aged women. Med. Sci. Sports Exerc. 1981; 13: 60-4.

15 Albanes D, Blair A, Taylor PR. Physical activity and risk of cancer in the NHANES I population. Am. J. Public Health 1989; 79: 744-50.

16 Martínez ME, Giovannucci E, Spiegelman D, Hunter DJ, Willett WC, Colditz GA. Leisure-time physical activity, body size, and colon cancer in women: Nurses' Health Study Research Group. J. Natl. Cancer Inst. 1997; 89: 948-55.

17 Lee I, Paffenbarger RS, Hsieh C. Physical activity and risk of developing colorectal cancer among college alumni. J. Natl. Cancer Inst. 1991; 83: 1324-9.

18 Taylor CB, Sallis JF, Needle R. The relationship of physical activity and exercise to mental health. Public Health Rep. 1985; 100: 195-201.

19 Paffenbarger RS, Hyde RT, Wing AL, Hsieh CC. Physical activity, all-cause mortality, and longevity of college alumni. N. Engl. J. Med. 1986; 314: 605-13.

20 Paffenbarger RS, Hyde RT, Wing AL, Lee I-M, Jung DL, Kampert JB. The association of changes in physical-activity level and other lifestyle characteristics with mortality among men. N. Engl. J. Med. 1993; 328: 538-45.

21 Lee I-M, Hsieh CC, Paffenbarger RS. Exercise intensity and longevity in men. The Harvard Alumni Health Study. JAMA 1995; 273: 1179-84.

22 Villeneuve PJ, Morrison HI, Craig CL, Schaubel DE. Physical activity, physical fitness, and risk of dying. Epidemiology 1998; 9: 626-31.
23 Prentice AM, Jebb SA. Obesity in Britain: gluttony or sloth? Br. Med.J. 1995; 311: 437-9.

24 Pavlou KN, Krey S, Steffee WP. Exercise as an adjunct to weight loss and maintenance in moderately obese subjects. Am. J. Clin. Nutr. 1989; 49: 1115-23.

25 Van Dale D, Saris WHM, ten Hoor F. Weight maintenance and resting metabolic rate 18-40 months after a dietexercise treatment. Int. J. Obes. 1990; 14: 347-59.

26 King AC, Frey-Hewitt B, Dreon D, Wood P. Diet versus exercise in weight maintenance: the effects of minimal intervention strategies on long term outcomes in men. Arch. Intern. Med. 1989; 149: 2741-6.

27 DiPietro L, Kohl HW, Barlow CE, Blair SN. Improvements in cardiorespiratory fitness attenuate age-related weight gain in healthy men and women: the Aerobics Center Longitudinal Study. Int. J. Obes 1998; 22: 55-62.

28 Rissanen AM, Heliövaara M, Knekt P, Reunanen A, Aromaa A. Determinants of weight gain and overweight in adult Finns. Eur. J. Clin. Nutr. 1991; 45: 419-30.

29 Williams PT. Evidence for the incompatibility of age-neutral overweight and age-neutral physical activity standards from runners. Am. J. Clin. Nutr. 1997; 65: 1391-6.

30 Killoran A, Fentem P, Casperson C. Moving On: International Perspectives on Promoting Pbysical Activity. London: Health Education Authority, 1994.

31 US Department of Health and Human Services. Physical Activity and Health: a Report of the Surgeon General. Atlanta, GA: Centers for Disease Control and Prevention, National Center for Chronic Disease Prevention and Health Promotion, 1996.

32 Crespo CJ, Keteyian SJ, Heath GW, Sempos CT. Leisure-time physical activity among US adults. Results from the Third National Health and Nutrition Examination Survey. Arch. Intern. Med. 1996; 156: 93-8.

33 Jones DA, Ainsworth BE, Croft JB, Macera CA, Lloyd EE, Yusuf HR. Moderate leisure-time physical activity. Arch. Fam. Med. 1998; 7: 285-9.

34 Health Education Authority (HEA) and Sports Council. Allied Dunbar National Fitness Survey, a Report on Activity Patterns and Fitness Levels: Main Findings. London: Sports Council and HEA, 1992.

35 Health Promotion Agency for Northern Ireland. The Northern Ireland Health and Activity Survey: Main Findings. Belfast: HMSO, 1994.

36 Colhoun H, Prescott-Clarke P, eds. Health Survey for England 1994. OPCS Health Survey No. 4. London: HMSO, 1996.

37 Department of Education. A National Survey of Involvement in Sport and Pbysical Activity. Dublin: Department of Education, Health Promotion Unit, 1996.

38 De Almeida MDV, Graca $\mathrm{P}$, Afonso C, D'Amicis A, Lappalainen R, Damkjaer S. Physical activity levels and body weight in a nationally representative sample in the European Union. Public Health Nutr. 1999; 2: 105-13.

39 Cirera L, Tormo M-J, Chirlaque M-D, Navarro C. Cardiovascular risk factors and educational attainment in Southern Spain: a study of a random sample of 3091 adults. Eur. $J$. Epidemiol. 1998; 14: 755-63.

40 Sallis JF, Hovell MF, Hofstetter CR. Predictors of adoption and maintenance of vigorous physical activity in men and women. Prev. Med. 1992; 21: 237-51.

41 Harrington KE, Robson PJ, Kiely M, Livingstone MBE, Lambe J, Gibney MJ. The North/South Ireland Food Consumption Survey: survey design and methodology. Public Health Nutr. 2001; 4(5A): 1037-42.

42 World Health Organization (WHO). Obesity: Preventing and Managing the Global Epidemic. Geneva: WHO, 1998.

43 Office of Population Censuses and Surveys. Standard Occupational Classification, Vol. 3. London: HMSO, 1991; $39-53$. 
44 Central Statistics Office. Census 96 Occupations. Dublin: Central Government Publications, 1998.

45 Ainsworth BE, Jacobs DR, Leon AS, Richardson MT, Montoye HJ. Assessment of the accuracy of physical activity occupation questionnaire data. J. Occup. Med. 1993; 35: 1017-27.

46 Jacobs DR, Ainsworth BE, Hartman TL, Leon AS. A simultaneous evaluation of 10 commonly used physical activity questionnaires. Med. Sci. Sport Exerc. 1993; 25: 8191.

47 Folsom AR, Caspersen CJ, Taylor HL, et al. Leisure time physical activity and its relationship to coronary risk factors in a population-based sample: the Minnesota Heart Survey. Am. J. Epidemiol. 1985; 121: 570-9.

48 Folsom AR, Jacobs DR, Caspersen CJ, Gomez-Marin O, Knudsen J. Test-retest reliability of the Minnesota Leisure Time Physical Activity Questionnaire. J. Chronic Dis. 1986; 39: 202-11.

49 Ainsworth BE, Haskell WL, Leon AS, Jacobs DR, Montoye HJ, Sallis JF, Paffenbarger RS. Compendium of physical activities: classification of energy costs of human physical activities. Med. Sci. Sports Exerc. 1993; 25: 71-80.

50 Stephens T, Jacobs DR, White CC. A descriptive epidemiology of leisure-time physical activity. Public Health Rep. 1985; 100: 147-58.

51 Stephens T. Secular trends in adult physical activity: exercise boom or bust? Res. Q. Exerc. Sport 1987; 58: 94-105.

52 Caspersen CJ. Physical activity epidemiology: concepts, methods, and applications to exercise science. Exerc. Sports Sci. Rev. 1989; 17: 423-73.

53 Wareham NJ, Rennie KL. The assessment of physical activity in individuals and populations: why try to be more precise about how physical activity is assessed? Int. J. Obes. 1998; 22(Suppl. 2): S30-8.

54 Wareham NJ, Hennings SHJ, Day NE, Prentice AM. Feasibility of heart-rate monitoring to estimate total level and pattern of energy expenditure in a population-based epidemiological study: the Ely young cohort feasibility study. Br. J. Nutr. 1997; 78: 889-900.

55 Ainsworth BE, Richardson M, Jacobs DR, Leon AS. Gender differences in physical activity. Women Sport Phys. Activity J. 1993; 2: 1-16.

56 Cauley JA, LaPorte RE, Sandler RB, Schramm MM, Kriska AM. Comparison of methods to measure physical activity in postmenopausal women. Am. J. Clin. Nutr. 1987; 45: 1422.

57 Weller I, Corey P. The impact of excluding non-leisure energy expenditure on the relation between physical activity and mortality in women. Epidemiology 1998; 9: 632-5.

58 Richardson MT, Leon AS, Jacobs DR, Ainsworth BE, Serfass R. Comprehensive evaluation of the Minnesota Leisure Time Physical Activity Questionnaire. J. Clin. Epidemiol. 1994; 47: 271-81.

59 DiPietro L. Physical activity, body weight, and adiposity: an epidemiologic perspective. Exerc. Sport. Sci. Rev. 1995; 23: 275-303.
60 Blair SN, Kohl HW, Barlow CE. Physical activity, physical fitness, and all-cause mortality in women: do women need to be active? J. Am. Coll. Nutr. 1993; 12: 368-71.

61 Mensink GB, Deketh M, Mul MD, Schuit AJ, Hoffmeister H. Physical activity and its association with cardiovascular risk factors and mortality. Epidemiology 1996; 7: 391-7.

62 Fogelholm M, Mannisto S, Vartiainen E, Pietinen $P$. Determinants of energy balance and overweight in Finland 1982 and 1992. Int. J. Obes. 1996; 20: 1097-104.

63 Livingstone MBE, Strain JJ, Prentice AM, Coward WA, Nevin GB, Barker ME, Hickey RJ, McKenna PG, Whitehead RG. Potential contribution of leisure activity to the energy expenditure patterns of sedentary populations. Br. J. Nutr. 1991; 65: 145-55.

64 Seidell JC, Rissanen AM. Time trends in the world wide prevalence of obesity. In: Bray GA, Bouchard C, James WPT, eds. Handbook of Obesity. New York: Marcel Dekker, 1998; 79-92.

65 DiPietro L. Physical activity in the prevention of obesity: current evidence and research issues. Med. Sci. Sports Exerc. 1999; 31(Suppl.): S542-6.

66 Lissner L, Heitmann BL, Bengtsson C. Low-fat diets may prevent weight gain in sedentary women: prospective observations from the Population Study of Women in Gothenburg, Sweden. Obes. Res. 1997; 5: 43-8.

67 Twisk JWR, Kemper HCG, van Mechelen M, Post GB, van Lenthe FJ. Body fatness: longitudinal relationship of body mass index and the sum of skinfolds with other risk factors for coronary heart disease. Int. J. Obes. 1998; 22 : 915-22.

68 Williamson DF, Madans J, Anda RF, Kleinman JC, Kahn HS, Byers T. Recreational physical activity and 10 -year weight change in a US national cohort. Int. J. Obes. 1993; 17: 279-86.

69 French SA, Jeffery RW, Forster JL, McGovern PG, Kelder SH, Baxter JE. Predictors of weight change over two years among a population of working adults: the Healthy Worker Project. Int. J. Obes. 1994; 18: 145-54.

70 Haapanen N, Miilunpalo S, Pasanen M, Oja P, Vuori I. Association between leisure time physical activity and 10year body mass change among working-aged men and women. Int. J. Obes. 1997; 21: 288-96.

71 Coakley EH, Rimm EB, Colditz G, Kawachi I, Willett W. Predictors of weight change in men: results from the Health Professionals Follow-Up Study. Int. J. Obes. 1998; 22: 8996.

72 Wong MY, Day NE, Wareham NJ. Measurement error in epidemiology: the design of validation studies II: the multivariate situation. Stat. Med. 1999; 18: 2831-45.

73 King AC, Haskell WL, Taylor CB, Kraemer HC, Debusk RF. Group- vs home-based exercise training in healthy older men and women: a community-based clinical trial. JAMA 1991; 266: 1535-42.

74 Perri MG, Martin AD, Leermakers SF, Sears SF, Notelovitz M. Effects of group- versus home-based exercise in the treatment of obesity. J. Consult. Clin. Psychol. 1997; 65: $278-85$. 